
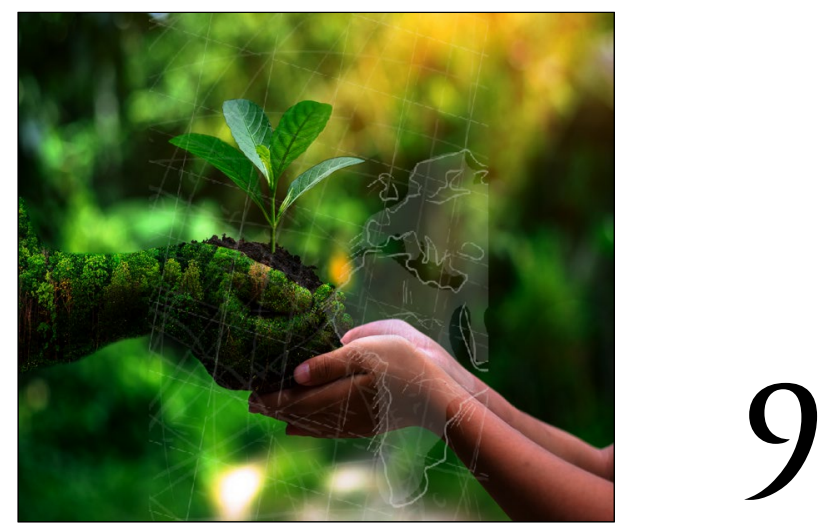

\title{
INDICATORS \\ ON TRANSFORMATIONAL INFRASTRUCTURE FOR A WELLBEING ECONOMY
}

\author{
Desta Mebratu
}

\section{Introduction}

As the term suggests, an 'indicator' is an instrument that provides an indication generally used to describe and/or give an order of magnitude to a given condition. There is a significant similarity between the terms 'indicator' and 'index' and the terms are sometimes used interchangeably. However, there are important differences at the level of aggregation and representation. Indicators generally provide information on the historical and current state of a given system and are particularly useful to highlight trends that can shed light on causal relations among the elements composing the system. On the other hand, an index is a composite statistic - a measure of changes in a representative group of individual data points, or in other words, a compound measure that aggregates multiple indicators. Indices are particularly useful to summarise and rank specific observations based on aggregating multiple indicators. 
Various indicators have been developed over many decades to measure economic and social development. Gross domestic product (GDP), which is used to indicate the trend in economic growth of national economies, is probably the most prominent and famous among these indicators. During the latter part of the twentieth century, economists tried to find ways to relate economic growth with social development. Arguably, the most prominent among the indicators and indices which emerged is the human development index (HDI), which was pioneered by the Nobel Laureate, Amartya Sen. The need for developing a set of indicators to measure progress towards sustainable development, covering economic social and environmental sustainability, was globally recognised at the United Nations Conference on Environment and Development (UNCED) held in Rio de Janeiro in 1992. A different set of sustainable development indicators and indices have been developed since then.

The urgency for transformational change in national development efforts received unprecedented global consensus and support in 2015. This resulted in the adoption of Agenda 2030 on Sustainable Development Goals (SDGs) and the signing of the Paris Agreement on Climate Change. At the regional level, Africa endorsed its own Agenda 2063, which aspires to transform the region along the line of Agenda 2030. As noted in the first chapter of this book, Africa has a unique opportunity to seize this transformational moment and leapfrog to a more inclusive, low-carbon and resource-efficient economy.

The overall purpose of this chapter is to provide a framework for measuring the progress of African countries in building the transformational infrastructure that are covered in this book as a basis for the transition to a wellbeing economy. The chapter provides a review of economic development indicators with a focus on GDP as a national development indicator and the alternative indicators related to sustainable development. This is followed by a discussion on key principles and procedures pertaining to sustainable indicators and sustainability assessment. The final section provides a generic framework for a 'leapfrogging indicator to a wellbeing economy' that could be adopted and used by African countries.

\section{Economic development indicators}

Indicators are essential instruments in informing policy and decision-makers about the current state and future trends of a given system and/or process. The use of indicators for measuring organisational performance has been around for a couple of centuries. However, the use of indicators for measuring policy performance and development targets has become more significant in recent decades. A combination of different indicators might be necessary to describe complex phenomena, where different concurring causes and effects have to be measured and compared. As a 
general rule, the choice and combination of indicators should be based on available data, the information needed by policymakers, and policy priorities (Pintér, Hardi, Martinuzzi \& Hall, 2012).

Both quantitative and qualitative information can be used to define an indicator, depending on the issue that needs to be analysed, as well as on the availability and quality of data. Quantitative indicators provide a standardised and measurable description of a given phenomenon, thereby allowing for a more consistent and universal comparison across time and space. Qualitative indicators are often expressed quantitatively (e.g., ranks, percentages) to facilitate trend identification and comparison. According to the Organization for Economic Co-operation and Development (OECD), before being used for the analysis of trends and phenomena, indicators should be assessed against some essential features which include the following:

Policy relevance: The indicator needs to address issues that are of (actual or potential) public concern relevant to policy-making. The ultimate test of any single indicator's relevance is whether it contributes to the policy process.

Analytical soundness: Ensuring that the indicator is based on the best available science is an essential feature to ensure that the indicator can be trusted.

Measurability: The need to reflect the reality on a timely and accurate basis, and be measurable at a reasonable cost, balancing the long-term nature of some environmental, economic and social effects and the cyclicality of others. Definitions and data need to allow meaningful comparison across time and countries or regions. (OECD, 2010)

Since the middle of the twentieth century, GDP has been the most dominant economic development indicator and served well for the promotion of freemarket economy in the early twentieth century. However, alternative development indicators started to emerge during the latter part of the century as the dismal failure of the free-market economy in terms of addressing social injustices and environmental degradation became more and more evident. This section explores the main features of GDP and its limitations as a measure of economic development. This is followed by a brief review of the major indicators that have emerged as an alternative to GDP and the rationale behind it.

\section{Gross domestic product as an economic indicator}

Gross domestic product, as it was defined by its creator, is a measure of the market value of goods and services produced within an economy in a given period (Kuznets, 1934). It has, therefore, been a reasonable indicator to measure the level of economic production in a region or country. However, since its inception in 
the 1930s, GDP has garnered a disproportionate amount of attention and influence from both policymakers and the general public, who have come to see it not merely as a measure of economic production, but of human wellbeing and social progress more broadly (Nahman, Mahumani \& De Lange, 2016). Despite the recognition of its limitation as a measure for development by its creator, Thomas Kuznets, the unlimited use of GDP has made it the most powerful number in the world (Fioramonti, 2013). It has been a couple of decades since the limitations of conventional development indicators including GDP has been recognised. This became more pronounced as the limitation of neo-classical economics in effectively addressing environmental externalities and the failure of its 'trickle-down' theory in addressing inequality became more evident. Given the significant importance and attention given to GDP in national policy and planning processes, it is essential to understand its major limitations to be able to define appropriate interventions and corrective measures.

Besides the caution given by the economist on its use as a measure of human welfare (Kuznets, 1934), the limitations of GDP as an indicator of human wellbeing have been well documented by different experts and institutions (Commission of the European Communities, 2009; Fioramonti, 2013, Nahman et al., 2016; Pepper, Jackson \& Uzzell, 2009; Stiglitz, Sen \& Fitoussi, 2009; Van Den Bergh, 2009). This is because human wellbeing is, in the first place, determined by a wide range of factors, such as health, education, governance and political voice, social connections and relationships, social equity, environmental quality, meaningful work, leisure time, and spirituality, that are not adequately captured by GDP (Bartelmus, 2009; Costanza et al., 2007; Sen, 1985; Stiglitz et al., 2009). While GDP does tend to correlate with some of these factors (e.g., health and education), in other cases the relationship is weak, if not harmful (Nahman et al., 2016).

GDP also fails to account for the depletion of natural capital used in the production of economic goods and services, as well as the negative impacts of economic activity on human and environmental wellbeing (Arrow, Dasgupta \& Maler, 2003; Fioramonti, 2013; Hamilton, 1994, 1998; Harris, 2007; Van den Bergh, 2009). Indeed, because GDP only accounts for market transactions, social and environmental costs (such as crime and pollution) tend to be counted as 'benefits' in the calculation of GDP. On the other hand, socially beneficial activities occurring outside of formal markets, such as volunteer work and caregiving, are not counted in GDP (Fioramonti, 2013). As a result, the relationship between GDP and subjective measures of 'happiness' or 'quality of life' has been increasingly called into question. There is also mounting evidence that a narrow focus on GDP is at odds with the broader outcomes of sustainable development, particularly those relating to environmental wellbeing and social equity (Arrow et al., 2003; 
Ayres, 1995; Carson, 2010; Daly, 1996; Kallis, 2011; Latouche, 2010; Nahman \& Antrobus, 2005; Panayotou, 2000; Van den Bergh, 2011; Van den Bergh \& De Mooij, 2002).

Gross domestic product is measured on a seemingly infinite scale. This led to almost blind faith in economic growth that fuelled unlimited and unsustainable consumption and resulted in different forms of environmental degradation and social destruction. In the absence of a specified maximum threshold and of a more balanced set of indicators that are given the same prominence in policy discussions, the goal of modern societies has become to simply maximise GDP, irrespective of whether doing so actually improves wellbeing, and with little attention paid to the negative social and environmental consequences (Nahman et al., 2016). According to Fioramonti (2016), the growth ideology, which is reinforced by the neoliberal economists, was instrumental in building an idea of success that boosted markets and political conservative forces while producing massive inequalities, ecological mayhems and social conflicts.

In a recent report in the Finance and Development magazine, 'Neoliberalism: Oversold?', a group of IMF economists questioned the very foundations of the neoliberal approach to growth, arguing that the free-market reforms enforced since the 1980s have not generated development but simply increased inequalities (Fioramonti, 2013; Ostry, Loungani \& Furceri, 2016). An assessment of the specific policies related to the promotion of market competition through deregulation and limiting of state intervention as the two major planks of neoliberalism led the authors to three disquieting conclusions. Firstly, the benefits in terms of increased growth seem relatively difficult to establish when looking at a broad group of countries. Secondly, the costs in terms of increased inequality are prominent and such costs epitomise the trade-off between the growth and equity effects of some aspects of the neoliberal agenda. And thirdly, increased inequality, in turn, hurts the level and sustainability of growth and advocates of the neoliberal agenda need to pay attention to the distributional effects (Ostry et al., 2016).

Many attempts have been made to address the limitations of GDP as an economic and social development indicator by introducing additional indicators that cover economic and social costs. This includes the efforts made to develop an index of sustainable and economic welfare, a measure of economic welfare, and a genuine progress indicator. However, while these efforts represent some level of improvement on GDP, the primacy to economic outcomes over social and environmental outcomes is still dominant in the framing of these indicators. The HDI, which was spearheaded by the United Nations Development Programme (UNDP), has attempted to incorporate the social dimension in a more integrative way. However, this effort is based only on indicators relating to life expectancy, 
education (two indicators) and income - the environmental dimension is entirely neglected (Nahman et al., 2016). Other indicators, such as the ecological footprint and the environmental performance index (EPI), focus only on the environmental dimension and are, therefore, useful only as complements to social and economic indicators. Finally, the System of Environmental-Economic Accounting (SEEA) provides a rigorous and standardised methodology for integrating the economic and environmental dimensions but ignores the social dimension. The gross national happiness index is another emerging indicator that has been applied in a specific country context such as in the Kingdom of Bhutan.

\section{Sustainable development indicators}

The global effort on developing sustainable development indicators that address the economic, social and environmental dimension of sustainable development has received a new push since the 1990s. While some earlier initiatives could be considered as precursors, the importance of developing indicators for sustainable development received global recognition by the United Nations Conference on Environment and Development (UNCED) that was held in 1992. As was outlined in Chapter 40 of Agenda 21 endorsed during the conference, the critical need for quantitative indicators to drive policy formulation and implementation was recognised from the early stage of development of the concept of sustainable development (United Nations, 1992:347). In the 1990s, many indicator sets, dashboards and composite and aggregated indicators or indices have been developed by different institutions and research groups resulting in a plethora of indicators on sustainable development.

According to Eurostat (2014), the approaches and methods potentially applied to developing sustainable development indicator frameworks can be classified into two groups: policy-based approaches and conceptual approaches. The former uses existing policy and strategy documents as a frame of reference and are typically organised according to strategic issues and targets highlighted in the documents, while the latter includes a frame of reference independent from political priorities. Both approaches function differently with each having its own processes and objectives. However, they both have their place in supporting the different stages of a policy cycle that covers policy formulation, policy legitimisation, policy implementation, policy evaluation and policy change (Hak, Janoušková \& Moldan, 2016).

The United Nations Department of Economic and Social Affairs (UNDESA) stipulated that indicators for sustainable development have to be relevant, methodological sound, measurable, easy to communicate and access, limited in numbers and outcome-focused. The criterion for relevance is further comprised 
of links to the target, policy-relevance, and applicability at the appropriate level (UNDESA, 2007). Despite different concepts of policy cycles and diverse processes in the development of indicator frameworks, it seems clear that a rigorous indicator framework can be neither a purely conceptual framework nor only a policy-oriented frame of reference defined basically by specific development goals (Hak et al., 2016). This is because policy relevance and applicability at the appropriate level fall into the policy framework, while the link to the target is secured within the conceptual framework.

Lester King (2016) argues that in seeking to develop indicators with a maximised impact, one has to recognise that the function of selected indicators should be a significant determining factor. According to Melkers and Willoughby (2005), consistent top-level support, increased knowledge, and organisational capacity are the three primary drivers for an effective measurement system. Top-level support can be considered a political function of indicators since this is the basis for setting work programmes and focus. Hezri and Dovers (2006) call the knowledge function as the conceptual use of indicators, and the organisational capacity function as the instrumental use of indicators. Based on this, King provides the functional classification of sustainability indicators shown in Table 9.1.

Table 9.1 Functional classification table of sustainability indicators

\begin{tabular}{|l|l|l|l|}
\hline Value & Leadership functions & $\begin{array}{l}\text { Knowledge increase } \\
\text { functions }\end{array}$ & $\begin{array}{l}\text { Capacity assessment } \\
\text { functions }\end{array}$ \\
\hline Intrinsic (governance) & Political and operational & $\begin{array}{l}\text { Problem recognition and } \\
\text { awareness }\end{array}$ & Justificatory \\
\hline Extrinsic (general public) & Normative guidance & $\begin{array}{l}\text { Communication and opinion } \\
\text { forming }\end{array}$ & $\begin{array}{l}\text { Monitoring, control and } \\
\text { reporting }\end{array}$ \\
\hline
\end{tabular}

(Source: Adapted from King, 2016:23)

Intrinsic and extrinsic functions are described as the importance of sustainability indicators to the internal interests of governance groups versus public needs and wants. This difference is critical to recognise in developing indicator programs since different actors maintain different interests in the realm of public policy (Sommer, 2000). The important distinction here between this extrinsic dimension and the intrinsic dimension of the leadership function is that the former is meant to recognise the function of empowering the general public through normative guidance, while the latter is intended to recognise the integration of internal political directives from the leading governance units (King, 2016). On the other hand, indicators for the extrinsic dimension of the capacity function should be defined by the active participation and involvement of local citizens to provide an effective monitoring and control function. 
Bringing separate systems, represented by the balance between the economic, social and environmental considerations into a holistic framework for policy evaluation is the ideal intrinsic dimension of the knowledge function (Brugmann, 1997). Consideration of developing more robust indicators that fulfil the extrinsic dimension of the knowledge function of indicators include fostering communication and plurality of information and understanding the social and cognitive processes that affect public choices (Yli-Viikari, 2009). The administrative feature of the intrinsic dimension of the capacity assessment function focuses on justifying the governance position which includes resource needs, organisational improvements, employee motivation and operational control (Holzer \& Yang, 2004).

Experience from the last couple of decades has clearly shown that the development of sustainability indicators involves the most complex types of appraisal methodologies. This is particularly true in the absence of a systems-based approach and methodology. When one considers the issue of sustainability, fundamental uncertainties arise from the unpredictability of natural and social systems and the interactions between them. The very nature of complex adaptive systems involves at least two non-reducible sources of uncertainty (Garnåsjordet, Aslaksen, Giampietro, Funtowicz \& Ericson, 2012). Firstly, any quantitative representation based on a given set of measurable attributes sooner or later will become obsolete because of systems-evolutionary changes introducing new definitions of relevant attributes and issues (Georgescu-Roegen, 1976). Secondly, their organization of multiple hierarchical levels requires the adoption of different scales for their perception and representation (Allen \& Starr, 1982; Simon, 1962) and makes it impossible to adopt just a single mathematical model, no matter how complicated it might be (Giampietro, Allen \& Mayumi, 2006; Rosen, 2000).

The Stiglitz Commission recognises that uncertainty is normative, as they question how measures established today may be used to predict the valuations of future generations in situations that may have become very different (Stiglitz et al., 2009). Despite the uncertainty involved, there are numerous sets of sustainable development indicators that have been developed both through scientific research groups and the inter-governmental process. Some argue that there is a significant obsession with numbers that led to an indicators explosion while others call for new and better indicators (Hak et al., 2016; Morse, 2013; Riley, 2001). Neither the scientific community nor the users know whether this remarkable worldwide effort should be more coordinated and regulated or if the 'survival of the fittest' principle is still the most efficient one (Dahl, 2012). The United Nations Statistics Division (UNSD) sees an explicit need to structure the indicators for Sustainable Development Goals (SDGs) into a coherent framework to secure the completeness of the indicator sets and emphasise linkages among the indicators thereby avoiding arbitrariness in the selection process (UNSD, 2015). 


\section{Sustainability assessment and composite indicators}

This section discusses composite indicators related to sustainable development. It also considers green economy indicators and describes some of the initiatives currently underway aimed at developing green economy indicator sets.

\section{Sustainability assessment as a basis}

Concepts such as integrated assessment and sustainability assessment are introduced to offer new perspectives to impact assessment and indicators development geared towards planning and decision-making on sustainable development (Sala, Ciuffo \& Nijkamp, 2015). Devuyst (2001) defined sustainability assessment as a methodology that can help decision-makers and policymakers decide what actions they should take and should not take in an attempt to make society more sustainable. Verheem (2002) on the other hand states that the goal of sustainability assessment is to pursue that plans and activities make an optimal contribution towards sustainable development. According to Sala, Farioli and Zamagni (2013), performing a coherent sustainability assessment research calls for:

adopting a holistic approach for understanding the dynamic interaction between nature and society and assessing vulnerability and resilience of complex social-ecological systems;

moving from multi-disciplinarity via interdisciplinarity towards transdisciplinarity as characterised by functional integration of different methodologies and epistemologies, co-production of knowledge, strong links with specific social context and institutional settings, and the inclusion of relevant values and common goods perceptions (Lang et al., 2012);

having a normative function by addressing the strategic and operational questions of what viable transition pathways could be identified for coupled human-environment systems and strategies for finding solutions to sustainability problems (Wiek, Ness, Schweizer-Ries, Brand \& Fariolli, 2012);

promoting social learning and mutual feedback leading to co-production of knowledge with other stakeholder groups in a collective process of problem identification and resolution; and

dealing with uncertainties by adopting a probabilistic approach for the assessment of scenarios is essential to achieve robust decision-making (Funtowicz \& Ravetz, 1993).

There are different sets of principles employed by different research groups and institutions in carrying out sustainability assessments. Out of the available alternatives, the Bellagio Sustainability Assessment and Measurement Principles 
(STAMP), is considered to represent harmonisation of the major principles used by experts in the field. These principles were initially developed by a group of measurement practitioners who met at the Bellagio Centre in 1996 and was later updated by Pintér et al. in 2012. The following are the main elements of the Bellagio STAMP:

Guiding vision: Progress towards sustainable development should be guided by the goal of delivering wellbeing within the carrying capacity of the biosphere and ensuring it for future generations.

Essential considerations: Underlying social, economic, and environmental components of the system as a whole should be taken into account as well as the interactions thereof and their implications for decision-making, including trade-offs and synergies.

Adequate scope: The assessment of progress towards sustainable development should adopt an appropriate time horizon and geographical scope to capture both the short- and long-term effects and their local and global effects, respectively.

Framework and indicators: Sustainability assessment should be based on a conceptual framework as a basis for identifying core indicators and related reliable data, projections and models.

Transparency: Transparency of data and data sources, models, indicators and results are crucial as well as public access to the results.

Effective communication: It is necessary to use clear and understandable language to ensure effective communication and to attract the broadest possible audience as well as minimise the risk of misuse.

Continuity and capacity: Sustainability assessment needs to be complemented by a continuous monitoring phase that includes repeated measurement as well as responsiveness to change as a basis for continuous learning and improvement.

Broad participation: Sustainability assessment needs to find appropriate ways to strengthen legitimacy and relevance, engaging early on with users of the assessment, reflecting the views of the public while providing active leadership. (Pintér et al., 2012)

In general, as was noted by Rametsteiner, Pülzl, Alkan-Olsson and Frederilksen (2011), the development of sustainability indicators is a process of both scientific 'knowledge production' and of political 'norm creation', and both components need to be appropriately acknowledged. Studies conducted across different sets of indicators have shown that both groups were present in all sustainability 
indicator processes, albeit in varying degrees, both in design and in practical implementations). The challenging question is to determine what is better from having a slightly more accurate but politically less relevant set or a slightly less accurate but politically more relevant set. From practical expediency perspective, going for the latter option, with a built-in adjustment and improvement mechanism, could be more beneficial, particularly for developing countries.

\section{Composite indicators}

The use of composite indicators received much attention in the early decades of indicators formulation for sustainable development (Moldan, Janoušková \& Hak, 2012). Wilson, Tyedmars and Pelot (2007) identified the following as some of the main composite indicators related to sustainable development that developed in the 1990s and the subsequent decade:

Ecological footprint (EF): The EF provides a quantitative assessment of the biologically productive area (the amount of nature) required to produce the necessary resources (food energy and materials) and to absorb the wastes of a given population (Rees \& Wackernagel, 1996). The ecological footprint, therefore, ultimately measures the sustainability of human consumption patterns.

Environmental sustainability index (ESI): The ESI is a composite index targeting environmental, socio-economic and institutional indicators as a means to assess sustainability. An ESI incorporates 20 indicators, each of which has two to eight variables, for a total of 68 underlying datasets. The core components of an ESI include environmental systems, reducing stresses, reducing human vulnerability, social and institutional capacity, and global stewardship (World Economic Forum, Yale University \& Columbia University, 2002).

Wellbeing Index (WI): A WI is a composite index that evaluates human and ecosystem wellbeing. It is an equally-weighted average of the human wellbeing index (HWI) and the ecosystem wellbeing index (EWI). Both consist of five dimensions. The former comprising health and population, knowledge and culture, community and equity; the latter consists of land, water, air, species and genes, and resource use (Prescott-Allen, 2001).

Human development index (HDI): The HDI is one of the most widely recognised measures of development. It measures three dimensions of human development: a long and healthy life, knowledge, and decent standard of living (UNDP, 2004). HDI is used as a proxy of sustainability based on the rationale that high human development facilitates sustainable development. 
In recent years, a new metrics called gross happiness index (GHI) has been added to this group. The foundation for this index was laid by the United Nations High-Level Meeting called Wellbeing and Happiness: Defining a New Economic Paradigm, which was hosted by the Kingdom of Bhutan in 2012. The Kingdom of Bhutan is the first country that adopted gross national happiness as its primary development indicator instead of GDP. This has provided the basis for producing the World Happiness Report ${ }^{1}$ by the UN Sustainable Development Solutions Network.

As much as composite indicators may be useful in highlighting interesting differences between countries in ways that may contribute to improved knowledge, they can seldom be used as a basis for implementing specific policy measures (Garnåsjordet et al., 2012). Furthermore, different authors (OECD, 2008; Paruolo, Saisana \& Saltelli, 2011; Saisana, Saltelli \& Tarantola, 2005; Saltelli, 2007; Stiglitz et al., 2009) indicated that besides leading to severe normative questions, aggregation of incommensurable value dimensions might conceal differences in underlying indicators rather than clarifying them. Table 9.2 highlights some pros and cons of composite indicators as described by Saisana and Tarantola (2005).

Table 9.2 The pros and cons of composite indicators

\begin{tabular}{|c|c|}
\hline \multicolumn{2}{|c|}{ Composite indicators } \\
\hline Pros & Cons \\
\hline $\begin{array}{l}\text { - Can summarise complex or multi-dimensional } \\
\text { issues in view of supporting decision-makers }\end{array}$ & $\begin{array}{l}\text { - May send misleading policy messages if they are } \\
\text { poorly constructed or misinterpreted }\end{array}$ \\
\hline $\begin{array}{l}\text { - More straightforward to interpret than trying to } \\
\text { find a trend in many separate indicators }\end{array}$ & - May invite simplistic policy conclusions \\
\hline $\begin{array}{l}\text { - Can facilitate the task of ranking countries on } \\
\text { complex issues in a benchmarking exercise }\end{array}$ & $\begin{array}{l}\text { - May be misused, e.g., to support a desired policy } \\
\text { even if it lacks sound statistical or conceptual } \\
\text { principles }\end{array}$ \\
\hline $\begin{array}{l}\text { - Can assess the progress of countries over } \\
\text { time on complex issues }\end{array}$ & $\begin{array}{l}\text { - The selection of indicators and weights could be } \\
\text { the target of political challenge }\end{array}$ \\
\hline $\begin{array}{l}\text { - Can reduce the size of a set of indicators or } \\
\text { include more information within the existing } \\
\text { size limits }\end{array}$ & $\begin{array}{l}\text { - May disguise severe failings in some dimensions } \\
\text { and increase the difficulty of identifying proper } \\
\text { remedial action }\end{array}$ \\
\hline $\begin{array}{l}\text { - Can facilitate communications with the } \\
\text { general public and promote accountability }\end{array}$ & $\begin{array}{l}\text { - May lead to inappropriate policies if dimensions of } \\
\text { performance that are difficult to measure are ignored }\end{array}$ \\
\hline & $\begin{array}{r}\text { (Source: Adapted from Saisana and Tarantola, 2002, } \\
\text { as cited in Garnåsjordet et al., 2012:330) }\end{array}$ \\
\hline
\end{tabular}

Even if there are some limitations related to the use of composite indicators, it is believed that they can provide valuable insight into policy and decision-making, particularly in assessing progress towards agreed goals and targets. Hence, most organisations and governments use one or another form of composite indicators keeping in mind the possible limitations they may have. 


\section{Green economy indicators}

The recent global trend towards a 'green economy' has added renewed impetus to initiatives aimed at going 'beyond GDP'. The United Nations Environment Programme (UNEP) defines a green economy as one that results in improved human wellbeing and social equity, while significantly reducing environmental risks and ecological scarcities'; that is, an economy which is 'low carbon, resource efficient, and socially inclusive' (UNEP, 2011:16). Given the multiple economic, social and environmental objectives of a green economy, and the inherent limitations of GDP, an alternative (or at least expanded) set of indicators is required for measuring progress towards a green economy. Several initiatives are currently underway aimed at developing green economy indicator sets or frameworks. These include:

work on a green economy index (Nahman et al., 2016);

a green growth measurement framework (OECD, 2011);

work on measuring progress toward a green economy (UNEP, 2014);

the 'iGrowgreen'2 indicator-based assessment framework to identify countryspecific challenges in promoting greener growth (Eurostat, 2012);

the Wealth Accounting and Valuation of Ecosystem Services (WAVES) ${ }^{3}$ global partnership, which provides technical support for countries implementing the System of Environmental-Economic Accounting (SEEA); and

the Global Green Growth Institute (GGGI) indicators for green growth strategy and planning and the Green Growth Knowledge Platform, a global partnership between the GGGI, OECD, World Bank and UNEP, which is working towards a common framework of green growth indicators (Benson \& Greenfield, 2012).

The green economy indicators framework that was developed by UNEP provides a set of indicators that focus on measuring progress and trends at the different stage of the policy cycle with a particular focus on factors that facilitate the transition to a green economy. The framework identifies the following as the main stages of the policy cycle covered under the green economy indicators (UNEP, 2014):

Issue identification: These are instruments that help decision-makers to identify and prioritise problems that might undermine the path towards sustainable development. Four steps are proposed for the use of indicators in the issue

2 For more information on iGrowgreen: http://ec.europa.eu/environment/archives/ greenweek2011/sites/default/files/1-8_Bucher.pdf

3 More information can be found at: https://www.wavespartnership.org/ 
identification phase, namely: (i) identification of potentially worrying trends, (ii) assessing the issue and its relation to the natural environment,(iii) analysing more fully the underlying causes of the issue of concern, and (iv) analysing more fully how the issue impacts society, the economy and the environment.

Definition of policy goals and formulation: While indicators for issue identification help to frame the problem, indicators for policy formulation help to design solutions. The two key steps that constitute policy formulation are the identification of policy objectives and the identification of intervention options. A multi-stakeholder approach is required to ensure that different perspectives are considered and incorporated in the definition of policy objectives and targeted interventions.

Policy assessment phase: In this phase, expected economic, social and environmental effects of different policy options need to be measured with the help of impact indicators. Also, the advantages and disadvantages of each policy option need to be analysed to provide robust evidence in support of decision-making. Three steps that are suggested for this phase are (i) estimate policy impacts across sectors, (ii) analyse impacts on the overall wellbeing of the population, and (iii) analyse advantages and disadvantages and inform decision-making.

Policy monitoring and evaluation: Indicators for policy monitoring and evaluation support the assessment of the performance of the intervention implemented and allow decision-makers to design timely corrective measures when needed. The analysis should include an estimation of co-benefits and ancillary benefits for the economy as a whole, as well as the improvement of the wellbeing of the entire population.

This approach is consistent with the use of the DPSIR framework through the identification of Drivers (D), Pressures (P), State (S), Impacts (I) and Responses (R) (UNEP, 2008). While indicators for problem identification help to frame the issue, and indicators for policy formulation help to design solutions, impact indicators support the assessment of the cross-sectoral impacts of the interventions chosen. Finally, the use of monetary and financial indicators enables the evaluation of the feasibility of each intervention, comparing investment and avoided costs, or added benefits, depending on the issue to be solved.

Despite the numerous efforts on developing indicators related to a green economy, there has been little progress in developing a green economy dashboard or composite index that provides the same level of usability and simplicity offered by GDP. In addition, existing initiatives are primarily based on issues identified in the context of developed economies and as such tend to emphasise the economic and environmental dimensions of the green economy and to neglect social and broader 
developmental issues of relevance to many developing countries. Furthermore, the emphasis in existing green economy indicator frameworks tends to be on indicators of relative decoupling, that is, indicators of reduced resource use or environmental impact per unit GDP (e.g., $\mathrm{CO}_{2}$ emissions per \$ GDP). Indicators of absolute decoupling (reduced impact of the economy as a whole) are generally missing from these frameworks.

Indicators of relative decoupling, while necessary in terms of measuring the resource or emissions intensity of an economy, can be misleading. Total emissions, for example, can still be increasing, as long as they are rising at a slower rate than GDP. Furthermore, such indicators are susceptible to hiding the pollution that is shipped to developing countries if they are not designed from a life-cycle perspective. Indicators of relative decoupling, therefore, fail to reflect the urgency of the need for a transition toward a green economy. Given recent evidence suggesting that four out of the nine 'planetary boundaries' have already been exceeded (Steffen et al., 2015) and considering the need for urgent action on issues such as climate change, the focus should arguably be on indicators of absolute (rather than relative) decoupling. This may necessarily have to be on a per-capita basis (to reflect the difference in population size between countries) and over a specified period (e.g., $\mathrm{CO}_{2}$ emissions per capita per year).

\section{The proposed framework for leapfrogging indicators}

While many lessons could be drawn from existing literature and practical experience in developing and utilising sustainability-related indicators, the framework proposed in this chapter focuses explicitly on assessing the leapfrogging possibilities from transformative infrastructure. The first subsection of this section concentrates on presenting the most relevant considerations and criteria for selecting the relevant indicators. This is followed by a presentation of the proposed framework for developing and utilising indicators that can assist countries to assess their progress in laying the foundation for their transition to a wellbeing economy.

\section{Selection criteria for indicators}

As was noted by Stiglitz et al. (2009), measuring sustainability differs from standard statistical practice in a fundamental way as what is needed are projections of not only technological or environmental trends but also projections of how they will interact with socio-economic or even political processes. A fundamental property of any sustainability indicator is its ability to show changes over time. An indicatorbased sustainability assessment needs to address its historical development as well as its possible continuation into the future or provide early warnings of emerging threats to sustainability (Garnåsjordet et al., 2012). 
One of the major challenges faced by most developing countries is to identify and select the most relevant and practical set of indicators out of the hundreds of indicators proposed by different institutions and processes. There are a different set of criteria proposed for use by countries and governments in selecting the most relevant indicators. This chapter considers the criteria recommended by Cook, Saviolidis, Daviosdottir and Johannsdottir (2017). These criteria were developed through a two-stage approach, which involved focus group research that represents a bottom-up approach and indicator selection by a team of experts as a top-down approach. The criteria used by Cook et al. are as follows:

Policy relevance: Could the indicator be closely related to an existing or future policy target?

Utility: Did the indicator meet the needs of decision and policymakers and the public in being fundamentally understandable?

$\square$ Soundness: Did the indicator appear to be aligned with a consistent methodology for capturing the multiple components of environmental sustainability without presenting a risk of duplicating aspects?

Interpretability: Was the indicator able to communicate meaningful information concerning performance relative to environmentally sustainable outcomes?

Data availability and quality: Was the indicator based on sufficiently highquality data with adequate coverage over time?

\section{Proposed framework for transformative leapfrogging indicators}

The overall objective of the indicator framework for leapfrogging to a wellbeing economy is to assist African countries to develop the infrastructural foundations for building a wellbeing economy that is inclusive, low-carbon and resource-efficient. Such an economy ensures sustainable livelihood and wellbeing to its people and contributes to the global sustainability effort. In this section, we propose the preliminary skeleton structure of the framework for the leading indicators with a focus on the critical infrastructural elements that will determine the leapfrogging possibility of a country towards an inclusive, low-carbon and resource-efficient economy. As a framework, it needs to be adapted to the specific policy and operational context of each country for its effective implementation and use. To measure progress on building a transformative development trajectory towards a wellbeing economy, it focuses on the fundamental transformational foundations that provide the basis for the transition. It also looks at the most appropriate 
institutional context for effective operationalisation and implementation of the transformational process.

The fundamental building blocks of the framework for the leapfrogging indicators are defined on the combined consideration of the key principles of the Bellagio Sustainability Assessment and Measurement Principles (STAMP), as updated by Pintér et al. (2012), and the set of criteria proposed by Cook et al. (2017). The framework is also informed by the key issues and conceptual frameworks that have been highlighted in the preceding chapters of this book. The following are the major elements and features of the proposed framework for the leapfrogging indicators:

Guiding vision: African countries can transition to a wellbeing economy which will enable them to fulfil the basic needs and aspirations of their people while sustaining the wellbeing of the natural ecosystem as a foundation for their development.

Essential consideration: An internally driven and context-relevant transformative leapfrogging, as opposed to externally-driven incidental leapfrogging, is key in avoiding decisions that will lock African countries in unsustainable consumption and production patterns.

Adequate scope: The investment decisions to be made on essential infrastructure development within the coming five to ten years will determine African countries' leapfrogging opportunities to a wellbeing economy both in the medium and long term.

Framework and indicators: An African country's ability to effectively integrate the above consideration in their policy, planning and budgeting process is a crucial factor in determining its leapfrogging potential towards a wellbeing economy.

Selection criteria: The selection of the specific indicators needs to be based on their potential utility function, methodological soundness, ability for meaningful and effective communication, and data availability and quality.

Figure 9.1 shows the wellbeing economy development framework. As depicted, the framework for transformative leapfrogging indicators is structured under the three major components taking the above criteria and the related conceptual frameworks into consideration, namely transformative governance, transformative policy formulation and transformative policy formulation. 


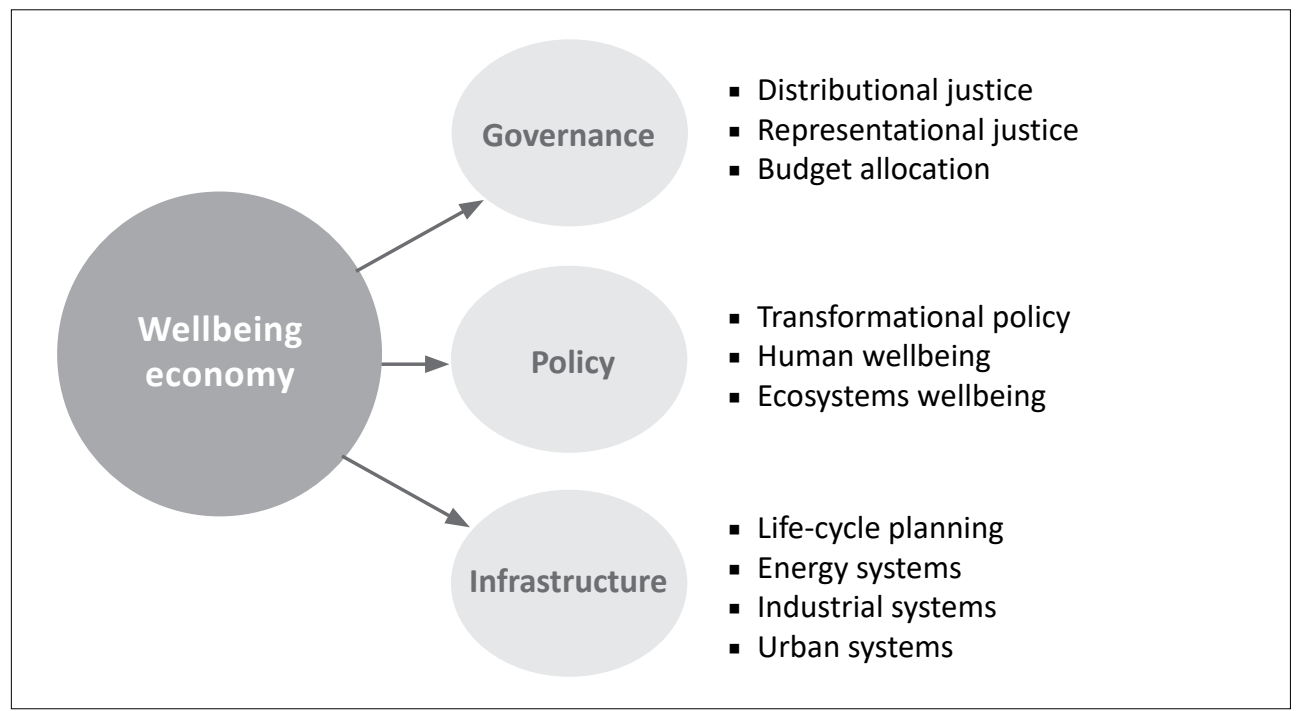

Figure 9.1 Wellbeing economy development framework

Transformative governance: Realising an effective governance system that fulfils both distributional and representational justice for communities is one of the primary prerequisites for achieving transformational development in the twenty-first century. This is mainly dependent on both the policy formulation and infrastructure development component, which may create practical constraints or act as facilitators for achieving distributional and representational justice. It is further reflected on the level of equitable allocation and effective utilisation of national budget allocation.

Transformative policy formulation: High-level political commitment expressed in the form of national policy and strategy document is critical for any country's progress towards a wellbeing economy that ensures both human and ecosystem wellbeing. This could range from incremental policy measures in specific sectors to a more comprehensive policy commitment that influences the national development trajectory. This can be assessed through the level of commitment for transformational development to wellbeing economy that promotes integrated consideration of human and ecosystem wellbeing and the policy preference given to transformative infrastructure development.

$\square$ Transformative infrastructure development: Decisions that are made on types of economic development infrastructure will determine the distributional effect of the whole economy besides determining the overall socio-economic and socio-ecological efficiency. It also determines the country's lock-in pitfalls and leapfrogging potential. The most critical factor in this process is the level of life-cycle consideration in the design and development of key 
economic infrastructure and the ability of countries to utilise existing and emerging knowledge, technology and systems that enhance the efficiency and effectiveness of their energy, industry and urban infrastructure.

Table 9.3 summarises the indicator framework for transformative leapfrogging.

Table 9.3 Indicator framework for transformative leapfrogging

\begin{tabular}{|c|c|c|}
\hline Foundations & Building blocks & Transformational indicators \\
\hline \multirow[t]{3}{*}{$\begin{array}{l}\text { Transformative } \\
\text { policy } \\
\text { formulation }\end{array}$} & $\begin{array}{l}\text { Macro-economic } \\
\text { policy and strategy } \\
\text { formulation }\end{array}$ & $\begin{array}{l}\text { 1. Level of integration of human and ecosystems wellbeing } \\
\text { dimensions in national policies and strategies (1-10) } \\
\text { 2. Fiscal policy preference and priority for transformative } \\
\text { infrastructure that promotes inclusive, low-carbon, and } \\
\text { resource-efficient development } \\
\text { 3. Policy level recognition for adaptive planning that combines } \\
\text { top-down with the bottom-up planning process }\end{array}$ \\
\hline & $\begin{array}{l}\text { Human wellbeing } \\
\text { improvement }\end{array}$ & $\begin{array}{l}\text { 4. Percentage increase in productive employment } \\
\text { 5. Percentage increase in basic service provisions (food health, } \\
\text { education, water, energy, etc.) } \\
\text { 6. Percentage improvement in gross happiness and wellbeing } \\
\text { index }\end{array}$ \\
\hline & $\begin{array}{l}\text { Ecosystems wellbeing } \\
\text { improvement }\end{array}$ & $\begin{array}{l}\text { 7. Percentage improvement in basic ecosystems services from } \\
\text { forests, wetlands, etc. } \\
\text { 8. Percentage reduction in } \mathrm{CO}_{2} \text { emission and improvement in air } \\
\text { quality } \\
\text { 9. Percentage increase in investment in nature-based } \\
\text { Infrastructure }\end{array}$ \\
\hline \multirow[t]{4}{*}{$\begin{array}{l}\text { Transformative } \\
\text { infrastructure } \\
\text { development }\end{array}$} & $\begin{array}{l}\text { Infrastructure planning } \\
\text { and development } \\
\text { process }\end{array}$ & $\begin{array}{l}\text { 10. Scope of life cycle considerations in planning, development, } \\
\text { and management of infrastructure }(1-10) \\
\text { 11. Level of cross-sectoral synergy and integration in infrastructure } \\
\text { planning and development }(1-10) \\
\text { 12. Reduction in the percentage of stranded assets in } \\
\text { unsustainable infrastructure }(1-10)\end{array}$ \\
\hline & $\begin{array}{l}\text { Transitioning to } \\
\text { sustainable energy } \\
\text { systems }\end{array}$ & $\begin{array}{l}\text { 13. Percentage of the total population with energy access } \\
\text { 14. Percentage increase in renewable energy share of total energy } \\
\text { generation } \\
\text { 15. Percentage increase in GDP per unit energy consumption as a } \\
\text { measure of energy efficiency }\end{array}$ \\
\hline & $\begin{array}{l}\text { Development of an } \\
\text { inclusive and resource- } \\
\text { efficient industrial } \\
\text { infrastructure }\end{array}$ & $\begin{array}{l}\text { 16. Level of horizontal and vertical integration of industries to the } \\
\text { local and national economy (1-10) } \\
\text { 17. Percentage of local value addition to the overall industrial } \\
\text { output and productivity } \\
\text { 18. Number of jobs created per unit of industrial investment } \\
\text { 19. Reduction in material energy and pollution intensity per unit } \\
\text { manufacturing output }\end{array}$ \\
\hline & $\begin{array}{l}\text { Development of urban } \\
\text { infrastructure }\end{array}$ & $\begin{array}{l}\text { 20. The multi-modality and functional synergy of urban } \\
\text { infrastructure } \\
\text { 21. Percentage improvement in job creation and value addition of } \\
\text { the urban economy } \\
\text { 22. The decline in the percentage of the population living in urban } \\
\text { slums }\end{array}$ \\
\hline
\end{tabular}




\begin{tabular}{|c|c|c|}
\hline Foundations & Building blocks & Transformational indicators \\
\hline \multirow[t]{3}{*}{$\begin{array}{l}\text { Transformative } \\
\text { governance }\end{array}$} & $\begin{array}{l}\text { Ensuring distributional } \\
\text { justice }\end{array}$ & $\begin{array}{l}\text { 23. Presence of conducive polity for a sustainable developmental } \\
\text { state } \\
\text { 24. Level of fair and equitable distribution of resources across } \\
\text { regions and communities } \\
\text { 25. Level of consideration for intra-generational justice in natural } \\
\text { resource management }\end{array}$ \\
\hline & $\begin{array}{l}\text { Ensuring } \\
\text { representational justice }\end{array}$ & $\begin{array}{l}\text { 26. Level of representational participation in planning and } \\
\text { management of development programmes } \\
\text { 27. Level of empowerment of women and youth groups in the } \\
\text { decision-making process }\end{array}$ \\
\hline & $\begin{array}{l}\text { Budget allocation and } \\
\text { utilisation }\end{array}$ & $\begin{array}{l}\text { 28. Percentage of the budget allocated for transformational } \\
\text { projects } \\
\text { 29. Level of decentralised and equitable allocation and } \\
\text { management of the budget } \\
\text { 30. The ratio of the additional leveraged resource with the } \\
\text { allocated budget }\end{array}$ \\
\hline
\end{tabular}

The indicators listed in Table 9.3 are a combination of quantitative and qualitative indicators. The non-quantifiable indicators listed can be assessed through proxy values, which can be converted to an aggregated value of $1-10$. Each country can measure its progress against the indicators either through an internal benchmarking that compares its performance with the previous years or through external benchmarking that compares its performance with a regional average value or any other country's performance.

\section{Conclusions}

Systemic transitions always involve complex dynamics that need to be understood and managed from the systems perspective. This task is even more complicated when it comes to social transformations. Fortunately, such moments of social transformations always come with some fundamental drivers that will essentially determine the most probable trajectory. The challenge for development practitioners and policymakers is to understand the dynamics between these primary drivers and manage their interactions for broader societal benefits.

Indicators are one of the most useful tools that help us to understand these dynamics and guide our policy and planning actions to steer the development process to the most desirable outcome. The significant volume of literature that is available on sustainability assessment and sustainable development indicators provides a useful foundation to make an informed decision on the best use of indicators.

As was noted in the previous chapters, the twenty-first century is a century in which humanity is faced with a historic moment of social transformation of a global proportion. In this context, African countries are faced with two important 
and historic choices. These are either being locked in the conventional 'growth economies' that are exclusive, inefficient and unsustainable or leapfrog into the 'wellbeing economy' that is inclusive, climate-resilient and resource-efficient economies of the twenty-first century.

The main objective of this book was to underline the critical importance of the path to be followed in developing a given country's socio-economic infrastructure in determining a country's economic future in this century. It also provided some of the major technical and decision-making tools that African countries could deploy in making the transition to a wellbeing economy. This final chapter of the book attempted to provide a framework of indicators that could be used as a basis for countries to assess their progress towards a more inclusive, low-carbon and resource-efficient economy. Needless to say, the framework needs to be adapted to the specific contexts of application to ensure its effective utility. 


\section{References}

Allen, T.F.H. \& Starr, T. (1982). Hierarchy: Perspectives for ecological complexity. Chicago: University of Chicago.

Arrow, K.J., Dasgupta, P. \& Maler, K.G. (2003). Evaluating projects and assessing sustainable development in imperfect economies. Environmental and Resource Economics 26(4): 647-685. https://doi.org/10.1023/ B:EARE.0000007353.78828.98

Ayres, R.U. (1995). Economic growth: Politically necessary but not environmentally friendly. Ecological Economics 15(2): 97-99. https://doi. org/10.1016/0921-8009(95)00073-9

Bartelmus, P. (2009). The cost of natural capital consumption: Accounting for a sustainable world economy. Ecological Economics 68(6): 1850-1857. https://doi.org/10.1016/j. ecolecon.2008.12.011

Benson, E. \& Greenfield, O. (2012). Surveying the 'green economy' and 'green growth' landscape. Working Draft for consultation. London: Green Economy Coalition.

Brugmann, J. (1997). Sustainability indicators revisited: getting from political objectives to performance outcomes. Local Environment 2(3): 299-302. https://doi. org/10.1080/13549839708725534

Carson, R.T. (2010). The environmental Kuznets curve: Seeking empirical regularity and theoretical structure. Review of Environmental Economics and Policy 4(1): 3-23. https://doi.org/10.1093/reep/rep021

Commission of the European Communities. (2009). GDP and beyond: Measuring progress in a changing world. Brussels: Commission of the European Communities.

Cook, D., Saviolidis, N.M., Daviosdottir, B. \& Johannsdottir, L. (2017). Measuring countries' environmental sustainability performance - The development of a nation-specific indicator set. Ecological Indicators 74: 463-478. https://doi. org/10.1016/j.ecolind.2016.12.009
Costanza, R., Fisher, B., Ali, S., Beer, C., Bond, L. et al. (2007). Quality of life: An approach integrating opportunities, human needs, and subjective wellbeing. Ecological Economics 61: 267-276. https://doi. org/10.1016/j.ecolecon.2006.02.023

Dahl, A.L. (2012). Achievements and gaps in indicators for sustainability. Ecological Indicators 17, June: 14-19. https://doi. org/10.1016/j.ecolind.2011.04.032

Daly, H. (1996). Beyond growth: The economics of sustainable development. Boston, MA: Beacon Press.

Eurostat. (2014). Getting messages across using indicators. Luxembourg: Eurostat.

Fioramonti, L. (2013). Gross domestic problem. London: Zed Books Ltd.

Funtowicz, S.O. \& Ravetz, J.R. (1993). Science for the post-normal age. Futures 25(7): 739-755. https://doi.org/10.1016/00163287(93)90022-L

Garnåsjordet, P.A., Aslaksen, L., Giampietro, M., Funtowicz, S. \& Ericson, T. (2012). Sustainable development indicators: From statistics to policy. Environmental Policy Governance 22(5): 322-336. https://doi. org/10.1002/eet.1597

Georgescue-Roegen, N. (1976). Energy and economic myth. New York: Pergamon Press.

Giampietro, M., Allen, T.F.H. \& Mayumi, K. (2006). The epistemological predicament associated with purposive quantitative analysis. Ecological Complexity 3(4): 307-327. https://doi.org/10.1016/j. ecocom.2007.02.005

Hak, T., Janoušková, S. \& Moldan, B. (2016). Sustainable development goals: A need for relevant indicators. Ecological Indicators 60: 565-573. https://doi.org/10.1016/j. ecolind.2015.08.003

Hamilton, K. (1994). Green adjustments to GDP. Resources Policy 20: 155-168. https://doi.org/10.1016/03014207(94)90048-5 
Harris, M. (2007). Towards genuine progress on the genuine progress indicator. Sydney: University of Sydney. https://doi. org/10.1504/IJEWE.2008.022259

Hezri, A. \& Dovers, S. (2006). Sustainability indicators, policy and governance: issues for ecological economics. Ecological Economics 60(1): 86-99. https://doi.org/10.1016/j. ecolecon.2005.11.019

Holzer, M. \& Yang, K. (2004). Performance measurement and improvement: an assessment of the state of art. International Review on Administrative Science 70(1): 15-31. https://doi. org/10.1177/0020852304041228

Kallis, G. (2011). In defence of degrowth. Ecological Economics 70(5): 873-880. https://doi.org/10.1016/j. ecolecon.2010.12.007

King, L.O. (2016). Functional sustainability indicators. Ecological Indicators 66: 121-131. https://doi.org/10.1016/j. ecolind.2016.01.027

Kuznets, S. (1934). National Income, 1929-32. 73rd US Congress, 2nd session, Senate document no. 124. Washington, DC, United States Congress. https://fraser. stlouisfed.org/title/971 [Accessed 15 September 2019].

Lang, D.J., Wiek, A., Bergmann, M., Stauffacher, M., Martens, P. et al. (2012). Transdisciplinary research in sustainability science: Practice, principles, and challenges. Sustainability Science 7(1): 25-43. https:// doi.org/10.1007/s11625-011-0149-x

Latouche, S. (2010). Degrowth. Journal of Cleaner Production 18: 519-522. https:// doi.org/10.1016/j.jclepro.2010.02.003

Melkers, J. \& Willoughby, K. (2005). Models of performance - measurement use in local governments: Understanding budgeting, communication and lasting effects. Public Administration Review 65(2): 180-190. https://doi.org/10.1111/j.15406210.2005.00443.x
Morse, S. (2013). Indices and indicators in development: An unhealthy obsession with numbers. London: Routledge.

Moldan, B. Janoušková, S. \& Hak, T. (2012). How to understand and measure environmental sustainability: Indicators and targets. Ecological Indicators, 17(1): 4-13. https://doi.org/10.1016/j. ecolind.2011.04.033

Nahman, A. \& Antrobus, G. (2005). The environmental Kuznets curve: A literature survey. South African Journal of Economics 73(1): 105-120. https://doi.org/10.1111/ j.1813-6982.2005.00008.x

Nahman, A., Mahumani, B.K. \& de Lange, W.J. (2016). Beyond GDP: Towards a green economy index. Development Southern Africa 33(2): 215-233. https://doi.org/ 10.1080/0376835X.2015.1120649

Organization for Economic Co-operation and Development. (2008). Handbook on constructing composite indicators. Methodology and user guide. Paris: OECD.

Organization for Economic Co-operation and Development. (2010). A framework to measure the progress of societies. OECD Statistics Working Papers No. 2010/05, OECD Publishing. Paris.

Organization for Economic Co-operation and Development. (2011). Towards green growth: Monitoring progress: OECD indicators. Paris: OECD.

Ostry, J.D., Loungani, P. \& Furceri, D. (2016). Neoliberalism: Oversold? Finance and Development 52(2): 38-41. https://bit. ly/2PASiOL [Accessed 10 January 2019].

Panayotou, T. (2000). Economic growth and the environment. CID Working Papers 56A, Center for International Development at Harvard University, Cambridge, MA.

Paruolo, P., Saisana, M. \& Saltelli, A. (2011). Ratings and ranking: Voodoo or science? Journal of the Royal Statistical Society Series A 176(3): 609-634. doi: 10.1111/j.1467985X.2012.01059 
Pepper, M., Jackson, T. \& Uzzell, D. (2009). An examination of the values that motivate socially conscious and frugal consumer behaviours. International Journal of Consumer Studies 33(2): 126-136. https://doi.org/10.1111/j.14706431.2009.00753.x

Pintér, L., Hardi, P., Martinuzzi, A. \& Hall, J. (2012). Bellagio STAMP: Principles for sustainability assessment and measurement. Ecological Indicators 17: 20-28. https://doi. org/10.1016/j.ecolind.2011.07.001

Prescott-Allen, R. (2001). The wellbeing of nation: A country-by-country index of quality of life and the environment. Washington, DC: Island Press.

Rametsteiner, E., Pülzl, H., Alkan-Olsson, J. \& Frederilksen, P. (2011). Sustainability indicator development - Science or political negotiation? Ecological Indicators 11(1): 61-70. https://doi.org/10.1016/j. ecolind.2009.06.009

Rees, W. \& Wackernagel, M. (1996). Our ecological footprint: Reducing human impact on earth. Gabriola Island, BC: New Society Publishers.

Riley, J. (2001). The indicator explosion: Local needs and international challenges. Agriculture, Ecosystems \& Environment 87(2): 119-120. https://doi.org/10.1016/ S0167-8809(01)00271-7

Rosen, R. (2000). Essays on life itself. New York: Columbia University Press.

Saisana, M., Saltelli, A. \& Tarantola, S. (2005). Uncertainty and sensitivity analysis techniques as tools for the quality assessment of composite indicators. Journal of the Royal Statistical Society Series A 168(2): 1-17. https://doi.org/10.1111/ j.1467-985X.2005.00350.x

Sala, S., Ciuffo, B. \& Nijkamp, P. (2015). A systemic framework for sustainability assessment. Ecological Economics 119: 314-325. https://doi.org/10.1016/j. ecolecon.2015.09.015

Sala, S., Farioli, F. \& Zamagni, A. (2013). Progress in sustainability science: lessons learnt from current methodologies for sustainability assessment. International Life Cycle Assessment 18: 1653-1672. https:// doi.org/10.1007/s11367-012-0508-6

Saltelli, A. (2007). Composite indicators between analysis and advocacy. Social Indicators Research 81: 65-77. https://doi. org/10.1007/s11205-006-0024-9

Sen, A.K. (1985). Commodities and capabilities. Amsterdam. North Holland Publishing Company.

Simon, H.A. (1962). The architecture of complexity. Proceedings of the American Philosophical Society 106(6): 467-482.

Sommer, F. (2000). Monitoring and evaluating outcomes of community involvement - the LITMUS experience. Local Environment 5(4): 483-491. https://doi. org/10.1080/713684888

Steffen, W., Richardson, K., Rockström, J., Cornell, S.E., Fetzer, I. et al. (2015). Planetary boundaries: Guiding human development on a changing planet. Science 347(6223) 1259855. https://doi. org/10.1126/science

Stiglitz, J., Sen, A. \& Fitoussi, J.P. (2009). Report by the Commission on Measurement of Economic performance and social progress. https://bit.ly/2CK9E6C [Accessed 20 September 2019].

United Nations Development Programme. (2004). Human development report 2004. New York: UNDP. https://doi. org/10.18356/68b83600-en

United Nations. (1992). United Nations sustainable development: Agenda 21. New York: United Nations.

United Nations Department of Economic and Social Affairs. (2007). Indicators of sustainable development: Guidelines and methodologies (3rd edition). New York: United Nations.

United Nations Environment Programme. (2008). SCP indicators for developing countries. A guidance framework. Paris: UNEP. 
United Nations Environment Programme. (2011). Towards a green economy: Pathways to sustainable development and poverty eradication. Nairobi, Kenya: UNEP.

United Nations Environment Programme. (2014). A guidance manual for green economy indicators. Nairobi, Kenya: UNEP.

United Nations Statistics Division. (2015). Discussion paper on principles of using quantification to operationalise the SDGs and criteria for indicator selection. ESA/ STAT/4412/2/58A/14. New York: UNSTAT.

van den Bergh, J.C. (2009). The GDP paradox. Journal of Economic Psychology 30(2): 117-135. https://doi.org/10.1016/j. joep.2008.12.001

van den Bergh, J.C. (2011). Environment versus growth - A criticism of 'degrowth' and a plea for 'a-growth'. Ecological Economics 70(5): 881-890. https://doi.org/10.1016/j. ecolecon.2010.09.035

van den Bergh, J.C. \& de Mooij, R.A. (2002). An assessment of the growth debate. In: J.C. van den Bergh (Ed.), Handbook of environmental and resource economics., Cheltenham, UK: Edward Elgar.
Wiek, A., Ness, B., Schweizer-Ries, A.W., Brand, F. \& Fariolli, F. (2012). From complex systems thinking to transformational change: A comparative study on the epistemological and methodological challenges in sustainability sciences projects. Sustainability Science 7: 5-24. https://doi.org/10.1007/s11625011-0148-y

Wilson, J., Tyedmers, P. \& Pelot, R. (2007). Contrasting and comparing sustainable development indicators metrics. Ecological Indicators 7(2): 299-314. https://doi. org/10.1016/j.ecolind.2006.02.009

World Economic Forum, Yale University \& Columbia University. (2002). The environmental sustainability index (ESI). Palisades, NY: NASA Socioeconomic Data and Applications Center (SEDAC). https://doi.org/10.7927/H4SB43P8

Yli-Viikari, A. (2009). Confusing messages of sustainability indicators. Local Environment 14(10): 891-903. https://doi. org/10.1080/13549830903255405 